\title{
Prevention of orthopaedic infection in spine surgery
}

\author{
Effrosyni Koutsoumpeli ${ }^{1}$, Nikolaos Koutsoumpelis²
}

'KAT Athens General Hospital, Greece; ' Department of Traumatology, BHS-Hospital Ried im Innkreis, Austria

\begin{abstract}
Surgical site infection (SSI) in spine surgery is a complication that increases not only the time of patient-recovery and the mortality but also the duration of hospitalization and subsequently the total hospital costs. The objective of this review is to identify the preventable risk factors, to reduce SSI in spine surgery. There are several factors that are associated with an increased risk of postoperative SSI. Some of them are associated with the health status of patient (ASA score >2, diabetes, obesity, smoking, urinary tract infection or incontinence, hypertension), while others with the surgical procedure (hand and instrument antisepsis, revision surgery, invasiveness, CSF leak, dural tear, blood loss, transfusion) and the compliance of the patient. Preoperative patient optimization and perioperative strategies can minimize the risk of SSI. Understanding the pathogenesis is essential to develop prevention strategies and improve surgical outcomes.
\end{abstract}

Keywords: Prevention, Spine surgery, Surgical site infection

\section{Introduction}

Surgical infections in spine surgery is a complication that can delay wound-healing and recovery, add impairments and increase the morbidity, the mortality and the overall financial constraints ${ }^{1,2}$, Although the prophylaxis against infections has recently improved, the incidence of surgical site infections (SSI) varies from $0,7 \%$ to $16 \%^{3}$. According to clinical studies, the postoperative wound-infections are the third most commonly hospital infections after pneumonia and urinary tract infection ${ }^{1,2}$. The infection rate varies according to the relevant published literature, and risk factors are classified as: 1) patient-related factors and 2) procedure-related factors ${ }^{1,2,4,5}$. The latter is further divided into: i) pre-operative, ii) intra-operative and iii) post-operative risk factors ${ }^{1,6}$. The successful prevention of SSI is inevitably bound up coping with these risk-factors, as up to $60 \%$ as SSIs are preventable by using evidence-based guidelines ${ }^{1,6}$.

\section{Methods}

This review was based on literature obtained from MEDLINE PubMed, the Cochrane Library, Google scholar, medical books and the guidelines of Robert-Koch- Institut in Germany, as published in Springer journals.

\section{Background, definition, and classification}

The transfer of micro-organisms to a surgical site causing consequently an inflammation is commonly called surgical site infection (SSI) ${ }^{7}$. Very important for the prevention of SSIs is to understand the epidemiologicalbacteriological profile of SSIs, the pathogenesis of these infections as well as the wound and SSI classification. First of all, as SSIs are defined as all the infections that occur in a surgical site within in 1 month from the operation day or within 1 year for operations with spinal instrumentation. The infection rate of patients was found 3-5\% lower in cases where the procedures involved clean wounds, compared with contaminated or dirty wounds and body cavities $^{8}$. The contamination classification ${ }^{8,9}$ of surgical wounds includes

1) Clean wounds, mostly in elective cases with primary closure, without inflammation or invasion of the respiratory, the alimentary or the genitourinary tract.

2) Clean/contaminated wounds, were the procedure involves

The authors contributed equally. The authors declare no potential conflict of interest.

Corresponding author: Nikolaos Koutsoumpelis, Unfallchirurgische Abteilung, Krankenhaus BHS Ried, Schloßberg 1, 4910 Ried im Innkreis, Österreich

E-mail: nikolaos.koutsoumpelis@bhs.at nikos.kouts@yahoo.gr

Edited by: Konstantinos Stathopoulos

Accepted 6 March 2018 
the above-mentioned tracts, however without evidence of infection.

3) Contaminated wounds, which includes accidental wounds, spillage of gastrointestinal tract or incision in areas with non-purulent inflammation.

4) Dirty (old) wounds with necrotic tissue and clinical signs of infection, were the bacterial pathogens preexisted in the operative field.

The SSIs are classified according to CDCs and NHSN also in:

1) Superficial incisional infections (involving the skin and the subcutaneous tissue).

2) Deep incisional infections (involving deeper soft tissue like fascia and muscles).

3) Organ/space infections (involving any other part of the body that was affected during the surgical procedure) $)^{4,6}$.

\section{Bacteriological background}

The bacteriological background of the SSIs shows in 35$50 \%$ of the cases contamination with Staphylococcus aureus and in $23.02 \%$ with Escherichia coli, followed by Pseudomonas aeruginosa $(7,9 \%)$ and Citrobacter species $(7,9 \%)^{5,9}$. The antimicrobial profile showed a sensitivity of gram-positive isolates to vancomycin, teicoplanin und linezolid, whereas the gram-negative isolates showed a susceptibility to meropenem, piperacillin-tazobaktam and amikacin ${ }^{5}$.

Infection with Staphylococcus aureus is associated either with endogenous infection, as it is usually found cohabiting the skin and the nasal flora, or with intra-operative contamination from the environment and/or the surgical staff ${ }^{1,5}$. MRSAisolates were responsible for $35 \%$ of Staph. Aureus infections in primary cases and up to $47 \%$ in revision surgery 6

Contamination with gram-negative bacteria is associated with surgical procedures of the lower lumbar and the sacral spine ${ }^{9}$. Especially wound invasion with $\mathrm{E}$. coli is a sign of poor hospital hygiene ${ }^{5}$.

Contamination of the wound with Propionibacterium acnes, an anaerobic, slow-growing gram-positive bacterium of the skin flora, is a common cause of delayed SSI and is associated with the use of spinal instrumentation. As the incubation time for growth of this bacterium is prolonged, one needs further and appropriate microbiological handling in cases of suspected infection with it ${ }^{6}$.

\section{Risk factors and prevention measures}

\section{Patient-related risk factors}

As already mentioned, the risk factors are divided into patient and procedure-related factors ${ }^{1,2,4,5}$. Among the first ones are the non-compliance of the patient, ASA score $>2$, comorbidities like diabetes mellitus, and obesity with $\mathrm{BM}>30-35$, cachexia, smoking, urinary tract infection, hypertension, age, anemia, (nasal) colonization with MRSA, malignity and immunosuppression ${ }^{1,6}$. In order to lessen the risk of SSI in spine surgery an optimization of the patient prior to hospitalization is usually required ${ }^{1,6}$.

\section{Diabetes mellitus and glycemic control}

Patients with diabetes mellitus and especially with insulin-dependent DM have increased infection risk usually attributed to peri-operative Hyperglycaemia (>200 mg/ dl) ${ }^{1}$. On the other hand, patients with $\mathrm{HbA} 1 \mathrm{C}$ values $<7$ had according to Hikata et al. $\% \%$ infection rate ${ }^{6}$. Furthermore, patients with DM have worse patient-related outcomes up to 2 years after a spine surgery ${ }^{6}$. Thus, adequate glycemic control is strongly recommended both during the preoperative as well as the peri-operative period.

\section{Obesity}

Class II obesity is a risk factor for postoperative wound infection ${ }^{1}$. According to Meng et al the infection risk increases already by a $\mathrm{BMI}>30 \mathrm{~kg} / \mathrm{m}^{2}$ (I class obesity) ${ }^{6}$. An abdominal fat layer of more than $3 \mathrm{~cm}$ is associated in any case with a significantly increased infection risk. Therefore for elective surgical procedures in obese patients a weight reduction regime prior to the procedure is usually suggested ${ }^{1}$.

\section{Nutritional status / Cachexia / Malnutrition}

The association of the Malnutrition with postoperative morbidity and mortality has been proved. The first metaanalyses of clinical studies have additionally verified the importance of postoperative immunonutrition to the reduction of serious infections and of the hospitalization of patients ${ }^{1}$. Early postoperative enteral nutrition has shown in addition a (non-significant) reduction of wound infection risk in contrast to prolonged postoperative fasting ${ }^{1}$.

\section{Smoking}

Smoking delays wound healing and consequently can increase the infection rate ${ }^{1}$. According to Meng et $\mathrm{al}^{6,10}$ smoking increases the relative risk of infection 1,17 after spine surgery. In a literature review conducted by Thomsen et al was found that smoking cessation prior to surgery reduced surgical complications by $50 \%$. Smokers that ceased smoking or reduced tobacco consumption 6 weeks prior to a surgical procedure and 10 days after had significant less wound-associated complications (haematoma, infection) ${ }^{1}$. On the contrary other surveys don't verify smoking as an independent risk factor ${ }^{11}$. Certainly smoking has to be ceased at least 4 weeks prior to elective surgery 1,6,9,11-13, as cessation of less than 4 weeks does not impact the overall infection risk. A nicotine replacement combined with behavioral therapy yields the best results ${ }^{6}$.

\section{Immunosuppression}

Immunocompromised patients (HIV-infection, malignant Iymphoma, chronic haematopoietic disease/insufficiency) or patients under immunosuppressive medication (glucocorticoids, nucleosides analogues, TNF- or CD52 Antibodies etc.) have an increased risk of skin- and soft tissue infections ${ }^{1,14}$. These patients show not only a high infection rate but also a broad spectrum of infectious agents. Prevention strategies should be targeted at the 
preoperative reduction of the immunosuppression as well as at appropriate antimicrobial prophylaxis and the potential antimicrobial therapy'.

\section{Infection/Colonization with (potentially) pathogenic bacteria}

Urinary tract infections or colonization with potentially pathogenic bacteria like S. aureus is a known risk factor for SSIs ${ }^{1,15,16}$. Distant site infections (pulmonary/urinary system, gastrointestinal tract) should be screened and aggressively treated perioperatively'. MSSA-carriers are 2 to 3 times and MRSA- 8-10 times more likely to have an SSI ${ }^{6}$. Most Staphylococcus aureus infections moreover are endogenously acquired, and treatment of nasal carriage is one potential strategy for prevention ${ }^{17}$. A screening test with a PCR-analysis should be conducted by high-risk patients 5 days prior to surgery with a corresponding therapy with $2 \%$ muripocin ointment intranasally combined with $2 \%$ chlorhexidine gluconate showers for 5 days by an MRSA colonization ${ }^{1,6}$.

\section{Non-compliance / Urinary incontinence}

An urinary incontinence, as well as non-compliance, were found independently associated with increased risk of $\mathrm{SSI}^{6,18}$.

\section{Procedure-related risk factors}

The prevention measures have to target also risk factors that are not related to the health status of the patient. There are specific guidelines for the prevention of hospitalacquired infections, which are divided into pre-, peri- und postoperative measures ${ }^{1}$.

\section{Preoperative measures:}

\section{Preoperative hospital length of stay}

The preoperative hospital length of stay is associated with an increased risk for SSls $\mathbf{s}^{1,14,19,20}$. Thus the length of stay before the surgery should be as short as possible ${ }^{1}$.

\section{Preoperative antiseptic shower}

The skin is not sterile. Actually there is a permanent colony (resident flora) that inhibits fungal infections as well as the establishment of harmful bacteria. Bacteria that are transferred to skin from the environment or other people and stay there temporary are called transient flora. Aim of the washing is to remove the transient flora and some of the resident flora. Reducing/removing the skin microflora by preoperative bathing or showering with skin antiseptics is however unclear whether it reduces the incidence of $\mathrm{SSI}^{9}$. The conducted surveys failed to find significant data that would justify the preoperative antiseptic shower as a prevention measure against $\mathrm{SSIs}^{1,6,9}$. The clinical studies are currently contradictory ${ }^{21-23}$. As a result a preoperative bath with skin antiseptics is not recommended. However a carefully washing in the operating theatre to remove soil is advisable'.

\section{Antiseptic dressings}

Chlorhexidine impregnated dressings in orthopaedic surgery (in historical controlled studies) applied to the surgical site the previous night or the morning of the surgery have shown a significant reduction in SSI rate ${ }^{6}$. Unfortunately, there is no data regarding the spine surgery specifically.

\section{Preoperative skin shaving vs. chemical depilation}

It has been shown that skin shaving, especially $24 \mathrm{~h}$ or more before the surgery, is responsible for microscopical lesions that serve as a point of entrance for bacteria and consequently increase the wound infection rate ${ }^{1,24,25}$. For elective procedures, it is recommended to use a depilatory cream on the previous day, although the chemical depilation could cause skin irritations or allergic reactions. The skin shaving should be performed only by surgical-technical necessity ${ }^{1}$.

\section{Perioperative measures:}

\section{Skin antisepsis}

The skin preparation with antiseptics just prior to incision aims at the removing of bacteria of the surgical field. For the skin, sterilization are used different preparation solutions. The most commonly are iodine and chlorhexidine combined with isopropyl alcohol compounds ${ }^{6}$. The ideal preparation solution is unclear, although according to a meta-analysis alcohol-based preparations are likely superior to aqueous solutions. Additionally, chlorhexidine compared to povidoneiodine may decrease SSI rates ${ }^{6}$. There is no evidence regarding the application of the solution (from the centre to the periphery) on the surgical site' .

\section{Surgical hand antisepsis}

Hand antisepsis of the surgical staff in order to remove the skin mikroflora prior to procedure is an established prevention measure against SSIs. There are, like in patient skin sterilization, different types of hand antisepsis and antiseptic agents: 1) Aqueous scrubs with chlorhexidine gluconate or povidone iodine and 2) alcohol rubs, which are performed with alcohol-based agents. The effectiveness of the alcohol agents is based on their concentration (60$90 \%)^{7}$. Other antiseptic agents are quaternary ammonium compounds, hexachlorophene, triclosan, and chloroxylenol. By conducted studies, there was an evidence of low quality that chlorhexidine-gluconate scrubs reduce the numbers of the colony-forming units (CFUs) more effectively compared to povidone iodine (Furukawa 2005, Herruzo 2000, Perreira 1990) ${ }^{7}$. Moreover it was shown that alcohol rubs with additional antiseptic agents may reduce CFUs more than aqueous scrubs, although there was no firm evidence. On the other hand chlorhexidine antimicrobial activity is slower than that of alcohol but more persistent, as it binds to the outermost layer of skin (Larson 1990) ${ }^{7}$.

As the alcohol agents do not remove surface dirt ${ }^{7}$, it is recommended for visually dirty hands to perform a prewash, which however should not be performed just before the alcohol rub, as the hand moisture reduces its activity. This pre-wash should instead be performed by entering the changing room ${ }^{1}$. It is remarkable that alcohol, as well 
as chlorhexidine, are not sporicidal'. In case of potential contamination with bacterial spores, it is important the prewash to be performed with other antiseptic agents.

Regarding the use of hand brushes and nail picks, they are not recommended, as firstly there was found no clear difference in the number of CFUs ${ }^{1,9}$, and secondly, they can damage skin $^{9}$ (ACORN 2012, AfPP 2011, AORN 2010, WHO 2009).

Of course, rings/jewelry and long or artificial fingernails are not allowed, as they increase the gloves perforation risk and the risk of harboring of pathogens. The hands shall also be dry by putting the gloves on. This reduces the risk of gloves perforation and of skin irritation and increases the antimicrobial activity of alcohol rub'.

Regarding to the duration of hand antisepsis there was an evidence of a reduced number of CFUs by a 3-minute scrub compared to a 2-minute one (Wheelock 1997) ${ }^{7}$. As for the alcohol rub there is a recommendation from the RobertKoch-Institution in Germany of at least 3 minutes hand disinfection (EN 12791)'.

\section{Surgical drapes and incision drapes}

Besides the sterile surgical drapes, incision drapes are used in orthopaedics often to reduce the contamination rate of the surgical site. However the usefulness of incision drapes is doubted ${ }^{1,26}$. In addition a non-reliable adhesion to skin can lead to retention of potential contaminated body fluids ${ }^{1}$.

\section{Surgical gloves}

Double gloving has been proven to be an important preventive measure in orthopaedic surgery. Especially the removal of outer gloves prior to handling instrumentation in lumbar spine fusion with posterior approach showed a significant reduction of $\mathrm{SSI}^{6}$. Additionally the double gloving reduces the risk of SSI in cases of perforation of outer gloves ${ }^{6,27}$ whereas indicator gloves of different color allow an early detection of perforation ${ }^{6}$.

\section{Perioperative antibiotics}

The perioperative antibiotic prophylaxis reduces the risk of SSls ${ }^{1,6,28-30}$. The timing of dose administration is critical and should be from $2 \mathrm{~h}$ till $30 \mathrm{~min}$ prior to incision'. According to recent studies the administration of antibiotics within the last $30 \mathrm{~min}$ prior to incision decreases significantly the rate of $\mathrm{SSI}^{6}$. In cases where the surgery duration exceeds the $3-4 \mathrm{~h}$, the administration of another dose is recommended ${ }^{\prime}$. Antibiotic prophylaxis over the first $24 \mathrm{~h}$ is not recommended ${ }^{3,6}$.

The type of antibiotic prophylaxis is associated with the bacteriological background of SSIs ${ }^{1}$. Generally is used a broad spectrum antibiotic, commonly a first- or secondgeneration cephalosporin (or clindamycin in case of penicillin-allergy), which targets gram-positive bacteria and especially Staphylococcus aureus ${ }^{1,3,6}$. Vancomycin should be administered in patients with MRSA colonization ${ }^{3,6}$ and not routinely ${ }^{3}$. In paediatric deformities like neuromuscular scoliosis or in lumbar/sacral spine surgery gram-negative bacteria should be appropriate targeted ${ }^{31}$.

\section{Surgical clothing}

Sterile single-use or impregnated surgical scrub suits, as well as surgical masks and caps, are of great importance for the prevention of SSIs ${ }^{1}$.

\section{Asepsis and surgical technique}

The duration of the surgical procedure is associated with the risk of a SS|316,32. A longer exposure of the wound, an extended trauma with more than one surgical levels as well as a CFS leak or a dural tear increase the infection rate ${ }^{1,6,16,33}$. It is remarkable that at 5 hours of surgery there is a proven recontamination of the surgeon's hands with detectable recolonization, which demands gloves changing after $3 \mathrm{~h}^{34}$ and rescrubbing after $4,5 h^{35}$. In addition the use of spinal instrumentation as well as the number of surgical sutures and of the devitalized tissues are associated with higher inflammation rates ${ }^{1,6}$. Concerning separate blades, which are usually used for incising the skin and deeper tissues, its usefulness is not verified from bacteriological studies'.

A relative recent issue is the minimal invasive spine surgery (MIS) as only a small volume of deep tissue is exposed. Due to the small working surgical field, the potential dead space and the deep infection rates in MIS are proven to be lower ${ }^{28,29}$. However MIS is a demanding technique with a long learning period and consequently increased surgical duration and complications during this period ${ }^{30}$.

In regards to posterior surgical approaches it has been shown an increase 3 to 8 times of SSI compared with an anterior approach ${ }^{36-38}$. Thoracic und lumbosacral surgery as well as an elevated invasiveness index increase significantly the SSI rate ${ }^{39}$.

It is also well documented that an increased number of persons in the operating theatre during the surgical procedure is correlated with high SSI rates ${ }^{40}$.

\section{Betadine wound-irrigation}

Betadine is a known antiseptical solution, which is used to sterilization/antisepsis of the skin and the wounds. In dilutions of $0,5-4 \%$ it has an effectiveness against pathogens, including MRSA, whereas in dilutions of more than $5 \%$ it has a cytotoxicity ${ }^{6}$. In spine surgery, it has been proven that the use of $3,5 \%$ Betadine to wound irrigation reduces significantly the SSI rate without adverse outcomes $^{3.6}$. Wound-irrigation with Betadine in $3 \mathrm{~h}$ intervals is recommended ${ }^{41}$.

\section{Intra-wounds antibiotics (IWA)}

The use of IWA in spine surgery and especially of vancomycin-powder has minimal systemic exposure ${ }^{1,42}$ and therefore a low rate of associated nephrotoxicity and ototoxicity ${ }^{43}$, allowing higher drug levels within the surgical site ${ }^{1,42,44}$. Its use has shown a non-significant decrease of the SSI levels ${ }^{41,45}$. Therefore the use of IWA is recommended 
from the North American Spine Society only in patients with comorbidities or for those undergoing complicated spine surgery ${ }^{46}$. The development of vancomycin-resistant S. aureus is a concern by MIC of vancomycin below $4 \mu \mathrm{g} / \mathrm{mI}^{47}$.

Another concern is the increased risk of pseudarthrosis by local vancomycin use, as it declines the $\mathrm{Ph}$ and consequently, the osteoblast activity at concentrations over $3 \mathrm{mg} / \mathrm{cm}^{2}$, whereas concentrations of $6 \mathrm{mg} / \mathrm{cm}^{2}$ are associated with significant cell death, due to acidic $\mathrm{pH}^{43}$. However early studies about the lumbar fusion between patients with IWA and control groups didn't find a significant difference ${ }^{47}$.

\section{Wound drainage}

The drainage systems are divided into open and closed systems. The first ones are responsible for increased SSI rates and are not recommended, whereas the usefulness and the infection risk of the closed suction drainage are controversial ${ }^{1}$. It is known that the formation of postoperative haematomas can increase the SSI rate, as haematomas provide an excellent culture medium for bacteria ${ }^{48}$, increase potentially the incision tension and the spinal cord compression and finally can delay the wound healing ${ }^{49}$. A clinical study with the use of MRI showed a significantly lower size and incidence of haematomas on first postoperative day by closed suction drainage systems, however without significant difference in the clinical outcome at 6 months follow-up ${ }^{50}$. Neither the clinical studies found a significant difference concerning postoperative infection rates, wound dehiscence, blood loss or epidural haematomas between patients with or without closed drainage after a non-complex lumbar surgery ${ }^{48,49,51}$. The dressing saturation was higher in patients without drainage ${ }^{60}$. The routine use of closed suction drainage in single-level lumbar decompression should thus be avoided, as they can potentially cause a retrograde infection ${ }^{49}$. Their need for multiple level decompression, instrumentation surgery, anticoagulant therapy, trauma, and tumors or metastases has to be clarified ${ }^{49}$. When needed, they should be placed through a different incision and they should be removed as soon as possible'.

\section{Metastatic spine surgery}

The rates of SSI in spine surgery for tumor resection are increased ${ }^{18}$. In cases of metastatic spine surgery is recommended an immediate postoperative soft tissue reconstruction by plastic surgeons, in order to achieve a wound healing and prevent SSIs ${ }^{52}$. Intra-wound vancomycin, as well as percutaneous instrumentation (pedicle screws), could also be used in those patients 9 .

\section{C-arm contamination}

In a conducted study, cultures were obtained from the drapes of a C-arm in 25 cases of spine surgery ${ }^{45}$. It was found a contamination of the drapes in all cases. As a result all areas of a C-arm, especially the upper ones, should be considered intraoperatively non-sterile ${ }^{6}$.

\section{Antibiotic impregnated sutures - iodine coated implants}

A recent innovation in the prevention of SSI in spine surgery is the iodine coated implants ${ }^{42}$ as well as the use of antibiotic impregnated sutures, which prevent bacterial adherence. The cost of the impregnated sutures are very high but an economic benefit could be achieved by prevention $1 \mathrm{SSI}$ per 200 procedures per year. As for the iodine coated implants is a very promising technology with significant reduction of the SSI rate, however it is not yet trialed in large series ${ }^{52}$.

\section{Normothermia, euglycemia, oxygenation}

Among the measures that have to be taken peri- and postoperatively are the normothermia', the euglycemia and the preservation of a good oxygenation of the patient. Hypothermia during a surgical procedure increases the infection risk ${ }^{1,6}$, whereas warmed patients sustain fewer infections and require fewer antibiotics ${ }^{6}$. Regarding glycemic status, there is evidence that supports the decrease of SSI after successful management of perioperative hyperglycemia ${ }^{6,44,53}$. Last but not least was found that oxygen fraction of less of $50 \%$ intraoperatively increased 12 times the likelihood of $\mathrm{SSI}^{6}$.

\section{Postoperative measures:}

\section{Wound dressings}

The wound dressings provide physical support, protection from bacterial contamination and absorb exudate ${ }^{8}$. They are divided into basic, advanced and antimicrobial / silverimpregnated dressings. They support the wound-healing, thus preventing a SSI. Studies didn't show a significant difference in SSI rate between dressing removal after $48 \mathrm{~h}$ and delayed dressing removal (with continued dressing) ${ }^{8}$. Dressings, if not saturated, should be left in situ for 24-48h, in order to avoid a fibrin injury.

\section{Wound vacuum dressing}

The medical vacuum systems should be used in not primary closed wounds, as they improve tissue perfusion and oxygenation and reduce wound edge tension, thus enhancing wound healing ${ }^{18}$. However its' use in cases of potential epidural bleeding needs further investigation ${ }^{48}$.

\section{Surveillance}

Surveillance and interpretation of clinical, laboratory and radiological findings ${ }^{1}$ is important for an early diagnosis of complications and the prevention of a SSI.

\section{Conclusion}

The prevention of an inflammation in spine surgery is of outmost importance, as an infection can have devastating results. It requires the cooperation of the surgeon with the $\mathrm{GP}$, the anesthesiologist, the surgical staff and the ward nurses, in order to minimize the inflammation risks. Carrying out the preventive measures mentioned above reduces the rates an SSI and improves the quality of life of patients. 


\section{References}

1. Kommission der Krankenhaushygiene und Infektionsprävention beim Robert Koch-Institut. Prävention postoperativer Infektionen im Operationsgebiet. Springer Medizin Verlag Bundesgesundheitsbl Gesundheitsforsch - Gesundheitsschutz 2007:50:377-393.

2. Nota SP, Braun Y, Ring D, Schwab JH. Incidence of surgical site infection after spine surgery: what is the impact of the definition of infection? Clin Orthop Relat Res 2015;473(5): 1612-9.

3. Parchi PD, Evangelisti G, Andreani L, Girardi F, Darren L, et al. Postoperative Spine Infections. Orthop Rev (Pavia) 2015;7(3):5900.

4. Anderson DJ, Podgorny K, Berrios-Torres SI, Bratzler DW, Dellinger EP, et al. Strategies to prevent surgical site infections in acute care hospitals: 2014 update. Infect Control Hosp Epidemiol 2014;35(6):605-627

5. Negi V, Pal S, Juyal D, Sharma MK, Sharma N. Bacteriological Profile of Surgical Site Infections and Their Antibiogram: A Study From Resource Constrained Rural Setting of Uttarakhand State, India. J Clin Diagn Res 2015;9(10):DC 17-20.

6. Anderson PA, Savage JW, Vaccaro AR, Radcliff K, Arnold PM, et al. Prevention of Surgical Site Infection in Spine Surgery. Neurosurgery 2017;80(3S):S1 14-S123.

7. Tanner J, Dumville JC, Norman G, Fortnam M. Surgical hand antisepsis to reduce surgical site infection. Cochrane Database Syst Rev 2016;(1):CD004288.

8. Dumville JC, Gray TA, Walter CJ, Sharp CA, Page T. Dressings for the prevention of surgical site infection. Cochrane Database Syst Rev 2014;(9):CD003091.

9. Webster J, Osborne S. Preoperative bathing or showering with skin antiseptics to prevent surgical site infection. Cochrane Database Syst Rev.2015;(2):CD004985.

10. Meng F, Cao J, Meng X. Risk factors for surgical site infections following spinal surgery. J Clin Neurosci 2015;22(12): 1862-6.

11. Sorensen LT, Horby J, Friis E, Pilsgaard B, Jorgensen T. Smoking as a risk factor for wound healing and infection in breast cancer surgery. Eur J Surg Oncol 2002;28(8):815-20.

12. Lind J, Kramhoft M, Bodtker S. The influence of smoking on complications after primary amputations of the lower extremity. Clin Orthop Relat Res 1991;(267):211-7.

13. Nagachinta T, Stephens M, Reitz B, Polk BF. Risk factors for surgical-wound infection following cardiac surgery. J Infect Dis 1987; 156(6):967-73.

14. de Boer AS, Geubbels EL, Wille J, Mintjes-de Groot AJ. Risk assessment for surgical site infections following total hip and total knee prostheses. J Chemother 2001;13 Spec No 1(1):42-7.

15. Wong ES. Surgical Site Infections. 3rd. Baltimore: Lippincott, Williams \& Wilkins; 2004

16. Ee WW, Lau WL, Yeo W, Von Bing Y, Yue WM. Does minimally invasive surgery have a lower risk of surgical site infections compared with open spinal surgery? Clin Orthop Relat Res 20 14;472(6): 17 18-24.

17. Laupland KB, Conly JM. Treatment of Staphylococcus aureus colonization and prophylaxis for infection with topical intranasal mupirocin: an evidence-based review. Clin Infect Dis 2003;37(7):933-8.

18. Kasliwal MK, Tan LA, Traynelis VC. Infection with spinal instrumentation: Review of pathogenesis, diagnosis, prevention, and management. Surg Neurol Int 2013; 4(Suppl 5):S392-403

19. Meers P, McPherson M, Sedgwick J; Cheltenham. Infection Control in Healthcare, United Kingdom: Stanley Thornes; 1997

20. de Boer AS, Mintjes-de Groot AJ, Severijnen AJ, van den Berg JM, van Pelt W. Risk assessment for surgical-site infections in orthopedic patients. Infect Control Hosp Epidemiol 1999;20(6):402-7.
21. Hayek LJ, Emerson JM, Gardner AM. A placebo-controlled trial of the effect of two preoperative baths or showers with chlorhexidine detergent on postoperative wound infection rates. J Hosp Infect 1987; 10(2):165-72.

22. Garibaldi RA. Prevention of intraoperative wound contamination with chlorhexidine shower and scrub. J Hosp Infect 1988; 11 Suppl B:5-9.

23. Rotter ML, Larsen SO, Cooke EM, Dankert J, Daschner F, et al. A comparison of the effects of preoperative whole-body bathing with detergent alone and with detergent containing chlorhexidine gluconate on the frequency of wound infections after clean surgery. The European Working Party on Control of Hospital Infections. J Hosp Infect 1988; 11 (4):310-20.

24. Niel-Weise BS, Wille JC, van den Broek PJ. Hair removal policies in clean surgery: systematic review of randomized, controlled trials. Infect Control Hosp Epidemiol 2005;26(12):923-8.

25. Celik SE, Kara A. Does shaving the incision site increase the infection rate after spinal surgery? Spine (Phila Pa 1976) 2007; 32(15):1575-7.

26. Daschner $F$ et al. Einfluß von Plastikinzisionsfolien auf die postoperative Wundinfektionsrate? Chir Praxis 1984;34:357-358.

27. Laine T, Aarnio P. Glove perforation in orthopaedic and trauma surgery. A comparison between single, double indicator gloving and double gloving with two regular gloves. J Bone Joint Surg Br 2004;86(6):898-900.

28. O'Toole JE, Eichholz KM, Fessler RG. Surgical site infection rates after minimally invasive spinal surgery. J Neurosurg Spine2009; 11(4):471-6

29. Smith JS, Shaffrey Cl, Sansur CA, Berven SH, Fu KM, et al. Rates of infection after spine surgery based on 108,419 procedures: a report from the Scoliosis Research Society Morbidity and Mortality Committee. Spine (Phila Pa 1976) 2001;36(7):556-63.

30. Holly LT, Schwender JD, Rouben DP, Foley KT. Minimally invasive transforaminal lumbar interbody fusion: indications, technique, and complications. Neurosurg Focus 2006;20(3):E6.

31. Anderson DJ, Kaye KS, Chen LF, Schmader KE, Choi Y, et al. Clinical and financial outcomes due to methicillin resistant Staphylococcus aureus surgical site infection: a multi-center matched outcomes study. PLoS One 2009;4(12):e8305.

32. Culver DH, Horan TC, Gaynes RP, Martone WJ, Jarvis WR, et al. Surgical wound infection rates by wound class, operative procedure, and patient risk index. National Nosocomial Infections Surveillance System. Am J Med 1991;91(3B):152S-157S.

33. Whitehouse JD, Friedman ND, Kirkland KB, Richardson WJ, Sexton DJ. The impact of surgical-site infections following orthopedic surgery at a community hospital and a university hospital: adverse quality of life, excess length of stay, and extra cost. Infect Control Hosp Epidemiol 2002;23(4): 183-9.

34. Kirkland KB, Briggs JP, Trivette SL, Wilkinson WE, Sexton DJ. The impact of surgical-site infections in the 1990s: attributable mortality, excess length of hospitalization, and extra costs. Infect Control Hosp Epidemiol 1999;20(1 1):725-30.

35. Hosseini P, Mundis GM, Jr., Eastlack R, Nourian A, Pawelek J, et al. Do Longer Surgical Procedures Result in Greater Contamination of Surgeons' Hands? Clin Orthop Relat Res 2016;474(7): 1707-13.

36. Olsen MA, Lefta M, Dietz JR, Brandt KE, Aft R, et al. Risk factors for surgical site infection after major breast operation. J Am Coll Surg 2008;207(3):326-35.

37. Blam OG, Vaccaro AR, Vanichkachorn JS, Albert TJ, Hilibrand AS, et al. Risk factors for surgical site infection in the patient with spinal injury. Spine (Phila Pa 1976) 2003;28(13):1475-80.

38. Demura S, Kawahara N, Murakami H, Nambu K, Kato S, et al. Surgical site infection in spinal metastasis: risk factors and countermeasures. 
Spine (Phila Pa 1976) 2009;34(6):635-9.

39. Cizik AM, Lee MJ, Martin BI, Bransford RJ, Bellabarba C, et al. Using the spine surgical invasiveness index to identify risk of surgical site infection: a multivariate analysis. J Bone Joint Surg Am 2012;94(4):335-42.

40. Koutsoumbelis S, Hughes AP, Girardi FP, Cammisa FP Jr, Finerty EA, et al. Risk factors for postoperative infection following posterior lumbar instrumented arthrodesis. J Bone Joint Surg Am 2011;93(17):1627-33.

41. Gaviola ML, McMillian WD, Ames SE, Endicott JA, Alston WK. A Retrospective Study on the Protective Effects of Topical Vancomycin in Patients Undergoing Multilevel Spinal Fusion. Pharmacotherapy 2016;36(1):19-25.

42. Hayashi H, Murakami H, Demura S, Kato S, Yoshioka K, et al. Surgical site infection after total en bloc spondylectomy: risk factors and the preventive new technology. Spine J 2015; 15(1):132-7.

43. Boyce JM, Potter-Bynoe G, Dziobek L. Hospital reimbursement patterns among patients with surgical wound infections following open heart surgery. Infect Control Hosp Epidemiol 1990; 11(2):89-93.

44. Olsen MA, Nepple JJ, Riew KD, Lenke LG, Bridwell KH, et al. Risk factors for surgical site infection following orthopaedic spinal operations. J Bone Joint Surg Am 2008;90(1):62-9.

45. Ehlers AP, Khor S, Shonnard N, Oskouian RJ Jr, Sethi RK, et al. IntraWound Antibiotics and Infection in Spine Fusion Surgery: A Report from Washington State's SCOAP-CERTAIN Collaborative. Surg Infect
(Larchmt)2016;17(2):179-86.

46. Shaffer WO, Baisden JL, Fernand R, Matz PG, North American Spine S. An evidence-based clinical guideline for antibiotic prophylaxis in spine surgery. Spine J 2013;13(10): 1387-92

47. Strom RG, Pacione D, Kalhorn SP, Frempong-Boadu AK. Lumbar laminectomy and fusion with routine local application of vancomycin powder: decreased infection rate in instrumented and noninstrumented cases. Clin Neurol Neurosurg 2013; 1 15(9): 1766-9.

48. Kanayama M, Oha F, Togawa D, Shigenobu K, Hashimoto T. Is closedsuction drainage necessary for single-level lumbar decompression? review of 560 cases. Clin Orthop Relat Res 2010;468(10):2690-4.

49. Liu Y, Li Y, Miao J. Wound drains in posterior spinal surgery: a metaanalysis. J Orthop Surg Res 2016;1 1:16.

50. Mirzai H, Eminoglu M, Orguc S. Are drains useful for lumbar disc surgery? A prospective, randomized clinical study. J Spinal Disord Tech 2006; 19(3): 171-7.

51. Zijlmans JL, Buis DR, Verbaan D, Vandertop WP. Wound drains in non-complex lumbar surgery: a systematic review. Bone Joint $J$ 2016;98-B(7):984-9.

52. Mesfin A, Sciubba DM, Dea N, Nater A, Bird JE, et al. Changing the Adverse Event Profile in Metastatic Spine Surgery: An EvidenceBased Approach to Target Wound Complications and Instrumentation Failure. Spine (Phila Pa 1976) 2016;41 Suppl 20:S262-S270.

53. Lieber B, Han B, Strom RG, Mullin J, Frempong-Boadu AK, et al. Preoperative Predictors of Spinal Infection within the National Surgical Quality Inpatient Database. World Neurosurg 2016;89:517-24. 